\title{
Talent Conceptualization and Talent Management Approaches in the Vietnamese Banking Sector
}

\author{
Nhan Truong Thanh DANG ${ }^{1}$, Quynh Thi NGUYEN ${ }^{2}$, Raymund HABARADAS ${ }^{3}$, \\ Van Dung HA ${ }^{4}$, Van Thuy NGUYEN 5
}

Received: March 16, 2020 Revised: March 28, 2020 Accepted: June 02, 2020

\begin{abstract}
The research postulates the conceptualization of talent in the Vietnamese banking sector via examining the factors pertaining to the concept of talent and talent management (TM) in the sector. This study applied qualitative research methods. A total of 20 managers and directors of ten banks (three public, four private and three foreign banks) were recruited for semi-structured interviews. The findings revealed that a combination of interconnected soft skills, learning ability, flexibility, technology adaptability, integrity and risk management skills contributes to talent identification. Managers in some private banks construed talent to be commensurate with high performance and high potential, whereas managers in public banks and foreign banks mainly relied on performance results in talent recognition. Moreover, talented employees holding sales-related jobs are given the most attention by management in the studied banks. Regarding practical implications, the banking community and practitioners' focus should be imparted to soft skills development and integrity control in order to foster employee performance and attitudes. Attention should be paid not only to sales positions, but also to other positions within the bank. This study is one of a few which explores talent concepts and TM approaches in the banking sector in general and Vietnamese banking field in particular.
\end{abstract}

Keywords : Talent, Talent Conceptualization, Talent Management, Vietnam, Banking Sector

JEL Classification Code: E24, M12, M51

\section{Introduction}

Talent is varied, depending on industries and organisations (Iles, 2013; Gelens et al., 2015). Indeed, the 'talent' concept in the banking sector is utilized differently from the manufacturing and other service sector companies

${ }^{1}$ First Author. Banking University, Ho Chi Minh City, Vietnam / RMIT University, Vietnam. Email: nhandtt@buh.edu.vn

${ }^{2}$ RMIT University, Vietnam. Email: nguyentqbio@gmail.com

${ }^{3}$ De La Salle University, Manila, the Philippines.

Email: raymund.habaradas@dlsu.edu.ph

${ }^{4}$ Corresponding Author. Institute for Banking Science and Technology

Research, Banking University Ho Chi Minh City, Vietnam [Postal

Address: 39 Ham Nghi Street, District 1, Ho Chi Minh City, 70000,

Vietnam] Email: dunghv@buh.edu.vn

${ }^{5}$ Banking University, Ho Chi Minh City, Vietnam.

Email: thuynv@buh.edu.vn

(c) Copyright: The Author(s)

This is an Open Access article distributed under the terms of the Creative Commons Attribution Non-Commercial License (http://Creativecommons.org/licenses/by-nc/4.0/) which permits unrestricted noncommercial use, distribution, and reproduction in any medium, provided the original work is properly cited. due to the continuously changing nature of the banking sector (Soto, 2019). Banks are among the most highly regulated institutions in every country, with a large number of laws and regulations that govern their activities (Lucca et al., 2014). The banking sector has also globally witnessed multi-dimensional transformations in recent years. As stated by Deloitte (2019), the concurrent convergence of regulatory and market pressures create a unique environment for banks, of all sizes, to remain profitable, to devise strong compliance programs, and to seek growth opportunities. This has given rise to changes in talent recruitment in banks.

Banks' strategic changes in terms of regulations, customer segmentation and technology can only be supported by the right set of talent. Globally, due to a severe shortage in banking talents, banks are currently struggling with the challenges of attracting and retaining the right talent (Nzewi et al., 2015). There has been an increasing number of talent management (TM) studies in the banking industry in specific countries; most of those studies examined the role of TM strategy in their corresponding banking sector, investigated banks' TM practices and challenges, and 
evaluated the TM impact on employee performance. With regard to the Vietnamese context, human resource (HR) planning programs in the banking sector were sanctioned by the State Bank of Vietnam for the period 2011-2020. A number of public and private banks exerted concerted effort in developing capable HR (talent). Most commercial banks have improved their HR management schemes to attract and retain talent; however, their HRM (human resource management) practices still involve significant limitations in terms of cost management, strategy planning and leadership. Generally, some recently-developed HRM studies found that HR development is associated with key stages of the country's economic development (Zhu \& Verstraeten, 2013; Nguyen et al., 2018). Conversely, limited research focused on TM in the country's context. Those studies mainly investigated the ways of attracting and/or retaining Vietnamese talent without a clear focus on the conceptualization of talent (Kim et al., 2012).

Based on this gap, this study aims to address the following research questions:

- What are the factors (skills or abilities or job positions) considered in bank talent definitions?

- Which approach (inclusive or exclusive) is bank talent conceptualized based on?

This research would help to contribute to the theoretical development of talent concepts, enable the comparison with other industries in terms of how talent is defined, and contribute towards the enhancement of TM practices with a specific focus on the banking sector. In particular, this research responds to the call for greater sensitiveness to societal contexts and multi-level factors at work, which has been raised by many recent researchers, such as Ariss et al. (2013), and Cooke et al. (2014)

\section{Literature Review}

\subsection{Talent Conceptualization}

According to Hasan (2016), the discussion on the definition of the word 'talent' can be viewed through two distinct perspectives. The first perspective is the definition of talent in the context of the world of work, as elaborated by Gallardo-Gallardo et al. (2013), whereas the second perspective is elaborated from Meyers et al. (2013) point of view who defined talent as either innate or acquired.

Gallardo-Gallardo et al. (2013) used the object and subject approaches to explain the talent concept. Within the object approach, talent can be measured based on a set of criteria, including natural ability, mastery of systematically developed skills, commitment and motivation, and fit between an individual talent and the working context (Gallardo-Gallardo et al., 2013, Do et al., 2020). The perception of talent as skills and abilities were supported in several studies such as Silzer and Church (2010). Tansley et al. (2007) and Höglund (2012) further argued that specific skill sets of talents need to be developed in accordance with the requirements of job positions and organization demands.

The 'talent as subject' approach can be either inclusive or exclusive (Iles et al., 2010). The inclusive approach defines the term talent as everyone in the firm who possesses strength and whose successes can potentially create added value to it (Buckingham \& Vosburgh, 2001). In contrast, the exclusive approach is based on the perception of workforce segmentation, and considers talent as an elite division of the organization's population (Tansley et al., 2007). It includes talent as high performers and high potentials. Potential is defined as the possibility that individuals can become something more than what they currently are (Silzer \& Church, 2010). The exclusive approach is widely defended in the literature and is the most widespread approach to TM found in HR practice (Ready et al., 2010).

The debate of the inclusive versus exclusive viewpoints concentrates on the majority of talent in the population of the organization. Therefore, for HR managers, knowing which principle they should follow in allocating their resources (i.e., employees) is necessary. It is indicated that the inclusive perspective is more of a strength-based approach, compared to the exclusive perspective where workforce differentiation is applied (Hasan, 2016).

\subsection{Talent Management in the Banking Sector}

Given the current technology transformation environment, banks compete for skilled people not only with their traditional sector rivals, but also against a new wave of competition from technology giants and start-ups. The workforce changes and new skills become significantly important, bank leaders have been forced to think differently about how talent fits within their strategy from the top down.

Previously, banks used to focus mostly on accountants and commerce graduates to run their businesses. Nowadays there is a marked shift towards recruiting engineering and technology-oriented graduates (Shukla \& Nayak, 2016). Talent with the ability to apply new technologies and use it as a source of innovation in current banking products is highly required. Notably, the evolution of digital banking has led to the development of digital bank talents and other certain key roles in the organization that require specific skill sets. This breed of employees possesses high responsiveness to technological advancement and other specific skill sets, such as organizational agility, flexibility and adaptability. Besides, the transformation of banks to provide more value-added advisory services requires a talented workforce equipped with communication, advisory and negotiation skills, with affinity to deep customer centrism and understanding. Additionally, in order to grow and compete in uncertain 
business environments, banks also strive for attracting and retaining talented risk management professionals who have high level of integrity. Talent pools will probably have experienced a massive shift in expertise toward better analytics and greater collaboration which are required to fulfill various changes led by banks' risk avoidance culture.

Remarkably, bank employees' performance is normally evaluated by Key Performance Indicators (KPIs). A multitude of KPIs can be applied to measure every type of transaction and service in a bank to accurately evaluate performance, profit, customer service, and more. KPIs generally evaluate banks' success and measure its performance in tangible ways quantitatively as well as qualitatively for their leadership and stakeholders.

TM has been found to be significantly related to employee performance in organizations (Luna-Arocas \& Morley, 2015) including banks (Mensah, 2015). The ability to effectively manage talents in commercial banks is central to employee performance and seems to form a strong association with employee commitment (Nzewi et al., 2015). Such may explain the reason why there has been an increasing number of TM studies in that sector in a number of specific countries, such as the research of Hosen et al. (2018) in Bangladesh, and Fawal and Mawlawi (2018) in Lebanon. Those research findings have contributed to the recognition and admission of the important role of TM strategies in driving bank performance and provide significant recommendations for effective TM in the banking industry. Additionally, they also deliver academic references on research literature and methodology, which foster further research on TM from different perspectives with different methods and in different contexts. However, to the best of the authors' knowledge, there is still a research gap in talent conceptualization in the banking sector in particular contexts. Filling this gap would help to contribute to the theoretical development of talent related literature.

\section{Research Methodology}

To capture the perception of Vietnamese banking sector employees on how they conceptualize talent and talent management, the research applied a qualitative research method. The study utilized semi-structured interviews with open-ended questions, which allowed the understanding of the influence of the research context. It also allowed the authors to be guided by the literature review (interview guide) while simultaneously gaining an in-depth understanding of the phenomenon through the interviewees' narratives (Saunders et al., 2015).

\subsection{Participants}

This research used the purposive and snowball sampling techniques. The purposive sampling helps to ensure that some criteria are addressed, such as the legal structure of banks, bank size and types of managers. Snowball sampling is a common technique for data collection, best suited to the Vietnamese culture, which is based on the notion of 'collective society'. The relations among family and community play a very important role. Therefore, authors' personal networks were utilized to gain access and obtain a significant sample size during the recruitment process.

Initially, a list of all banks operating in the country was acquired from the State Bank of Vietnam (updated until 2019). The selected banks were state-owned, privatelyowned and foreign banks, which are well-known in Vietnam and employ in excess of 1,000 employees.

Twenty interviews were conducted with bank managers as key actors (including general managers, line managers and HR managers), representing 10 banks that partook in the research. These managers are in charge of managing the most common functions, such as sales, customer relations, investment, credit management and HRM. Those functions contribute significantly to their corresponding bank's financial performance and general growth (Ha, 2019; Tran et al., 2019). Exploring the perceptions of these managers is valuable since they are not only managers who assume TM responsibilities, but they also have first-hand experience as recipients of TM practices themselves (Cooke et al., 2014).The participants' relatively young age range (between 30 and 40 ) is commensurate with managerial positions that are open to the consideration of emerging issues, such as TM. The public bank is coded as PU, private bank is coded as PR, and foreign bank is coded as FO. Table 1 presents the codes of the participating banks and particulars of the participants, respectively.

\subsection{Participant Approach Procedure}

In order to attain a high response rate, the authors used their network of students, colleagues and families to approach the first four participants (LM1PU1, GM1PU2, HRPR1, and GM1PR1). These four participants introduced GM2PU2, GM2PR1, GMPR2, LM2PU1, and LM1PR3 to the authors via the word of mouth method. GM2PR1, LM2PU1 and LM1PR3 later introduced the other private and public banks' interviewees. The authors also had the opportunity to approach HRFO1 and HRFO2 in a TM workshop that took place at an international education institute. HRFO1 later introduced GMFO1 and HRFO3. The introduced interviewees, especially the ones from public banks, hesitated at first, but later accepted the invitation as they were ensured about the confidentiality of the interviews and data analysis. The reference method was suitable in this case as it is difficult to persuade participants without a prior relationship.

The interviewees were contacted via phone/face-to-face. Once they verbally agreed to join the study, an introductory 
Table 1: Particulars of Participants (created by authors)

\begin{tabular}{|c|c|c|c|c|}
\hline \multicolumn{5}{|c|}{$\begin{array}{c}\text { General managers (branch directors and transaction } \\
\text { office heads) }\end{array}$} \\
\hline Code & Age & Gender & Experiences & Bank \\
\hline GM1PU2 & 38 & M & 12 & PU2 \\
\hline GM2PU2 & 40 & $M$ & 13 & PU2 \\
\hline GMPU3 & 35 & $M$ & 7 & PU3 \\
\hline GM1PR1 & 39 & $\mathrm{~F}$ & 12 & PR1 \\
\hline GM2PR1 & 33 & $\mathrm{~F}$ & 7 & PR1 \\
\hline GMPR2 & 33 & $M$ & 8 & PR2 \\
\hline GMFO1 & 32 & $\mathrm{M}$ & 5 & FO1 \\
\hline \multicolumn{5}{|c|}{ HR manager } \\
\hline HRPR1 & 30 & $\mathrm{~F}$ & 5 & PR1 \\
\hline HRPR2 & 33 & $\mathrm{~F}$ & 10 & PR2 \\
\hline HRFO1 & 35 & $\mathrm{~F}$ & 9 & FO1 \\
\hline $\mathrm{HRFO} 2$ & 40 & $M$ & 12 & FO2 \\
\hline HRFO3 & 33 & $\mathrm{M}$ & 6 & FO3 \\
\hline \multicolumn{5}{|c|}{$\begin{array}{c}\text { Line managers and team leaders in specific } \\
\text { departments }\end{array}$} \\
\hline LM1PU1 & 29 & $M$ & 6 & PU1 \\
\hline LM2PU1 & 31 & $\mathrm{~F}$ & 7 & PU1 \\
\hline LMPR2 & 31 & $\mathrm{~F}$ & 7 & PR2 \\
\hline LM1PR3 & 31 & $M$ & 7 & PR3 \\
\hline LM2PR3 & 33 & $M$ & 8 & PR3 \\
\hline LM3PR3 & 35 & $\mathrm{~F}$ & 10 & PR3 \\
\hline LM1PR4 & 34 & $\mathrm{~F}$ & 12 & PR4 \\
\hline LM2PR4 & 33 & $\mathrm{~F}$ & 10 & PR4 \\
\hline \multicolumn{5}{|l|}{ Total } \\
\hline 20 & $\begin{array}{c}\text { Mean }= \\
34\end{array}$ & $\begin{array}{l}M=10 \\
F=10\end{array}$ & Mean = 8.7 & \\
\hline \multicolumn{5}{|c|}{$\begin{array}{c}\text { Public bank }-\mathrm{PU}=3 \\
\text { Private bank }-\mathrm{PR}=4 \\
\text { Foreign bank }-\mathrm{FO}=3 \\
\text { Total banks }=10\end{array}$} \\
\hline
\end{tabular}

letter and a participation consent form were sent to them. A convenient meeting time and venue (their offices/coffee shops) were then confirmed via phone and email.

\subsection{Interview Questionnaire Design and Transcription Procedure}

The interview questions, which were prepared in advance to ensure consistency throughout all interviews, were designed based on the research objectives, as well as on previous qualitative studies on TM (Cooke et al., 2014; Thunnissen \& Buttiens, 2017).

The question flow, content and wording were discussed amongst all authors prior to finalizing the questionnaire. The interview started with simple questions about the interviewee's background. The following questions revolved around specific experiences that the interviewee had with TM issues and gradually led to their perceptions of talent and TM. The questions of 'what happened', 'when', 'where", 'how' and 'why' were included. The questions and interview guide were translated into Vietnamese and double-checked for linguistic adjustments and rewording by two Vietnamese researchers of the team.

One researcher within the team was in charge of organizing the interviews. She followed the interview guide and the interview question set carefully, yet flexibly. Each interview was audio-recorded with the interviewee's permission and lasted for approximately one hour. The Vietnamese version of the questionnaire was used for the Vietnamese interviewees, while the English one was for foreign interviewees. It was later transcribed into a full and accurate word-for-word document rendition of the questions and answers. The Vietnamese answers were further translated into English, with a validation review undertaken by all authors.

\subsection{Data analysis}

The qualitative analysis technique applied in this study is thematic analysis. The steps involve in the thematic analysis included familiarizing the authors with the data, generating initial codes based on the research questions (such as talent skills and abilities; talent job positions; inclusive approach vs exclusive approach), searching for themes, reviewing, defining and naming themes (as per the subheadings in the findings and analysis section) and producing the report. The study uses NVivo to input scripts from word documents, perform the coding, add comments and screen out themes. Within each theme, the data from different types of banks is compared and generalized; meanwhile, the differences among various types of managers are not yet explored in depth, which can be a suggestion for future studies. The transcripts are read repeatedly five times in order to understand the conversations and samples that interviewees described. The themes and patterns are cross-checked among researchers while reading the transcripts.

\section{Findings}

\subsection{Talent as the Combination of Soft Skills, Integrity and Risk Management Skills}

There are six main tenets of including soft skills, learning ability, flexibility, technology adaptability, attitude and risk 
management skills, which participants addressed in the interviews when asked about their perception of talent. The finding and discussion of the first four factors (soft skills, learning ability, flexibility and technology adaptability) are investigated by Dang et al. (2019).

One third of the interviewees mention integrity. Participants refer to integrity as the mentality of bank employees to comply with rules and regulations (compliance) as well as their honesty and trustworthiness. This characteristic is particularly articulated by foreign bank managers. HRFO1 observed that:

"I think the main difference in talent criteria between banking and other service industries is about talent attitude, or we can say, integrity..."

It indicates that, among different banking sectors, foreign banks are likely to have the most concerns about integrity and the compliance mentality of bank talents. This might be due to the strong risk-avoidance culture, established on the basis of management standardization and centralization norms instigated by the banks' headquarters in their respective home countries.

Integrity is related to risk management skills, which was strongly raised by many participants, especially foreign bank managers. Risk management requires specialized knowledge and understanding of the banking, finance and law fields. According to HRFO1 and HRFO2, their banks place great emphasis on avoiding risk, including credit, compliance and liquidity risks. With respect to public and private banks, due to the appearance of the Basel Framework (The Basel
Framework, 2019) and the scandals surrounding bank corruption, there is an increasing demand for risk control ability (risk avoidance or limitation).

Risk control schemes also depend on individual branch managers' perspectives - 'risk appetite'. This is related to the decentralization level of a bank's system. The higher level of decentralization management system result in added independence while demanding higher discretion from branch managers. Discretionary behaviors of bank managers are mostly related to loan provisions and capital management. If the risk appetite of a manager is high, employees may be encouraged to have more flexibility and relax their risk assessment standards. Meanwhile, if the risk appetite of a manager is low, bank staffs are required to strictly follow the rules and be more relentless in evaluating risk. Table 2 presents the summary of the frequency of the talent skills and attitude as evident in the banks sampled.

\subsection{Talent in the Banking Sector in Relation to Sales}

Most of the participants believed that talents in the banking industry should be mainly related to the sales activity, which includes customer service or customer relationship. They explained that the reason for this perception is that sales is a primary activity which directly contributes to bank revenues and profits. Additionally, sales is also mainly quantitatively evaluated, e.g., through the number of sold units. This makes assessment and performance appraisal

Table 2: Summary of talent identification factors evident in Vietnamese banks sampled (created by authors)

\begin{tabular}{|c|c|c|c|c|c|c|}
\hline Bank & Soft skills & Learn ability & Flexibility & $\begin{array}{c}\text { Tech. } \\
\text { adaptability }\end{array}$ & Integrity & $\begin{array}{l}\text { Risk mana. } \\
\text { skills }\end{array}$ \\
\hline \multicolumn{7}{|c|}{ Public banks } \\
\hline PU1 & $\nabla$ & $\nabla$ & $\nabla$ & $\nabla$ & 凶 & $\nabla$ \\
\hline PU2 & $\nabla$ & 凶 & $\nabla$ & 冈 & $\nabla$ & $\otimes$ \\
\hline PU3 & $\nabla$ & $\nabla$ & 凶 & 凶 & 凶 & 凶 \\
\hline \multicolumn{7}{|c|}{ Private banks } \\
\hline PR1 & $\nabla$ & $\nabla$ & $\nabla$ & $\nabla$ & 凶 & $\nabla$ \\
\hline PR2 & $\nabla$ & $\nabla$ & $\nabla$ & $\nabla$ & 凶 & 凶 \\
\hline PR3 & $\nabla$ & 凶 & 凶 & $\nabla$ & 凶 & $\nabla$ \\
\hline PR4 & $\nabla$ & $\nabla$ & $\nabla$ & 冈 & 冈 & $\otimes$ \\
\hline \multicolumn{7}{|c|}{ Foreign banks } \\
\hline F01 & $\nabla$ & $\nabla$ & 凶 & $\nabla$ & $\nabla$ & $\nabla$ \\
\hline FO2 & $\nabla$ & 凶 & $\nabla$ & $\nabla$ & $\nabla$ & $\nabla$ \\
\hline FO3 & $\nabla$ & $\nabla$ & $\nabla$ & $\nabla$ & $\nabla$ & $\nabla$ \\
\hline TOTAL & 10 & 7 & 7 & 7 & 4 & 6 \\
\hline
\end{tabular}


simpler and clearer. For example, GMPU3, HRPR1 and HRPR2 mentioned that sales is considered as the most focused activity which requires significant investment from bank managers regarding recruitment, training, rewards and promotion. However, in foreign banks, managers mentioned that their TM programs are designed for a wide range of positions, but they equally admitted that, in comparison with back office jobs, sales seems to be simpler to evaluate.

Following the clarification of GMFO1 and LM3PR3, the banks' focus on sales jobs can be explained by their business strategies, operation complexity and demands. Banking business strategies are mainly related to customer centricity, growth, profitability and market expansion, which require a strong sales force. Building TM programs is also financially and resource costly, as emphasized by the participants. Consequently, banks' tendency to focus on sales function is understandable considering their budget limitations, demands and business strategies.

\subsection{Talent as High Performers/Potentials (Exclusive) Rather than All Employees (Inclusive)}

Most respondents classified talent in banks as high performers or high potentials (including staff or managers). In the case of public banks, most of the respondents raised the issue that talent is strongly related to performance (talent as high performer). They considered the seniority of employees as an important factor, which meant that they did not focus on fresh graduates or junior staff (even potential ones). This can be explained by the relatively high aging workforce in public bank management, who usually have conservative mindsets and are familiar with traditional HRM methods. According to typical HRM schemes in public banks, employee promotion occurs through time-consuming procedures (staff planning scheme) with various required approvals from different layers of management and support by colleagues via voting.

In terms of private banks which have established highly recognized TM programs, such as in the case of PR1 and PR2, in addition to the normal identification of talent as high performer (result), the consideration of talent as high potential (competency) also applies to the case of fresh graduates, newcomers and junior staff under their management schemes. Those potential talents are given opportunities and closely supported by leaders to improve even when their current performance results are not qualified.

However, in the case of the private banks which have not operated programs similar to TM, such as PR4, and the banks which have ever failed in those programs, such as PR3, their responses revealed that their banks mainly define talent as high performer (result-oriented perspective).
This is similar to the above public banks' perception. From their perspectives, working experiences are needed for bank employees to achieve high performance. Therefore, these private banks did not concentrate on fresh graduates, but rather identified high performers out of their current senior workforce. They also demonstrated a low tolerance for fresh or junior employees who had not yet adapted to the new working environment. When asked about the reasons for the failure of their TM programs, LM1PR3 explained that those programs should have trained existing staff and promoted them to senior manager positions, instead of training those who just graduated from school.

In terms of foreign banks, managers expressed their clear belief that talent identification should always be related to results, and that result data orientation would help to ensure the fairness and objectivity in talent recognition (talent as high performer). HRFO1 also mentioned that the KPI evaluation system in her bank is very clear and promotes the commitment of employees. The KPIs were self-determined by employees and later reviewed by their managers. All foreign banks' managers expressed the fact that their banks only selected a few persons annually, based on careful evaluation, and then submitted the talent lists to their respective overseas headquarters for a second review. The objectively selective assessment scheme has resulted in foreign bank managers developing strongly data-driven mindsets when identifying talent. The integrity culture has been expressed through the data driven thinking and result orientation of foreign bank managers in terms of HRM practices.

\section{Discussion}

\subsection{Talent as the Combination of Skills, Ability and Attitude}

Banks require their employees to develop a long-term bond with customers and implement the snowballing strategy. This gives rise to the need for talent who could act as a trusted advisor to such affluent customers and provide them with a diverse range of banking products and services which are cost-effective and technologically accessible (Kosim et al., 2016). Such demand has led to the requirements of different skills and abilities (see Figure 1).

As aforementioned, the first four factors including soft skills, learning ability, flexibility and technology adaptability were discussed in the study by Dang et al. (2019). Banking is different from other business activities via its moral aspects; extensive resources must be expended to ensure that all individuals in a bank are trustworthy and always act with integrity (Boatright, 2011). Integrity is one important characteristics if positively nurtured, developed and embedded into human capital would be of a great 


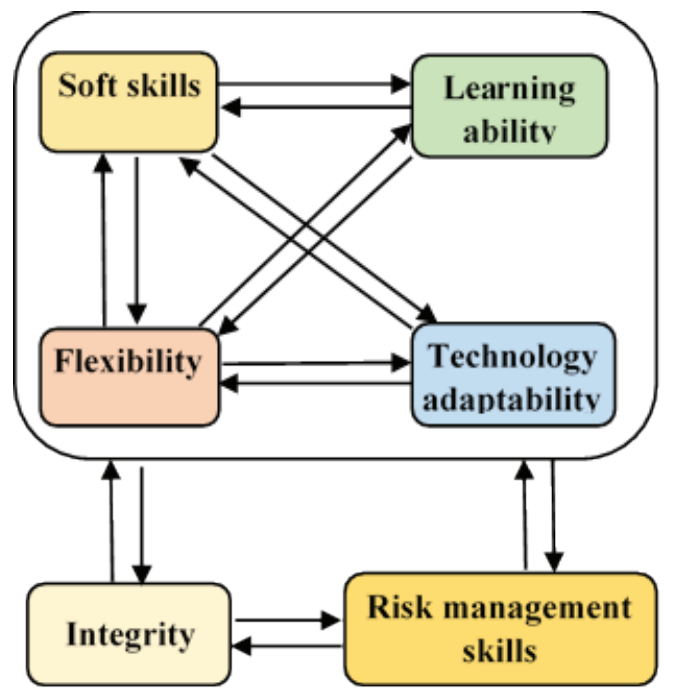

Figure 1: Interconnections between the Main Factors Contributing to Bank Talent (created by authors)

value-added talent and commodities while aligning with the organization's mission (Gaji et al., 2017).

As previously mentioned, foreign banks have the most concerns about this attribute of bank talents, possibly due to their sustainable culture of integrity established by the headquarters in their home countries. The interviewees made a common point that bank employees' integrity refers to a working attitude which is built from honesty and trustworthiness. This is the foundation on which coworkers build relationships, trust, and effective interpersonal relationships. This includes relationships with family, business partners, customers and vendors. Specifically, employees must avoid situations that might cause a conflict of interest or any charge of impropriety, real or implied. Most importantly, bank employees must comply with rules, regulations and follow appropriate protocols in task performing. Banks should take steps to ensure that staff, management, and bank officials act in compliance with the highest standards of integrity in accordance with best practice to avoid or minimize risks arising in connection with the bank's activities.

It is uneasy to monitor and measure integrity of employees, as admitted by the participants, as this attribute is not always explicitly revealed and it should be qualitatively evaluated. Until now, the banks studied in this research have attempted to assess employees' integrity based on the line managers' observation, feedbacks from customers and from colleagues. The foreign banks also include integrity factor in their scheme of 360 degree evaluation (also known as multi-source feedback, or multi-source assessment), which is a process through which feedback from an employee's subordinates, colleagues, and supervisors, as well as a self-evaluation by the employee themselves is gathered. However, the participants admitted that these approaches of measuring integrity is still formalistic and subjective and thereby sometimes not really effective in exploring the truths about employees' integrity.

Risk managing skills were mostly emphasized by the foreign banks' participants. Among different types of risks, the interviewees highlighted credit risk and compliance risk. A credit risk is the risk of default on a debt that may arise from a borrower failing to make required payments. Meanwhile, compliance risk is the risk of legal or regulatory sanctions, material financial loss, or loss to reputation a bank may suffer as a result of its failure to comply with laws, regulations, rules, related self-regulatory standards, and codes of conduct applicable to its banking activities (The Basel Framework, 2019).

Similar to integrity, it is not easy to suggest how banks can clearly evaluate the risk managing skills of employees. The interviewees expressed the concern that it takes significant time for employees to learn and experience about risk management. Based on experiences and observation, their risk handling skills may be improved gradually. Therefore, it also takes time for managers to evaluate the risk handling skills of their staff. Integrity and risk management are strongly correlated, as recognized by the participants. A bank employee who possesses a high level of integrity will have a better awareness of risk assessment and the motivation to limit or avoid risks. However, whether the correlations are positive or negative cannot be concluded yet, as the two-way impacts between integrity and risk management can be more complicated in reality.

These two factors also have interconnections and interdependence with soft skills, learning ability, flexibility and technology adaptability. However, the hypothesized interconnections among the factors are provided based on interviewees' personal opinions and the authors' critical thinking without quantitative testing.

\subsection{Talent in the Banking Sector Related to Sales}

Banks' focus on sales can be explained by means of different reasons. Firstly, this is the activity that directly contributes to banks' performance and mostly relates to their strategic objectives (Kosim et al., 2016). Secondly, the interviewees shared that banks have a wide range of jobs that are considered as sales such as credit specialists, customer relationship executives, business customer consultants, investment counsellor and even counters etc. Banks always have high recruitment demand for employees filling those job positions due to the pressure of growth and competition.

The third reason for banks' strong emphasis on sales is the fact the performance outcomes of these jobs are considered as easy to recognize and evaluate. Sales performance can 
be explicitly assessed in terms of both quantitative and qualitative evaluation. Some examples of quantitative sales performance indicators are numbers of units sold, numbers of contracts, percentage of customer increase; meanwhile, examples of qualitative indicators are customer satisfaction, employees' working attitude and managers' feedbacks based on observation. The quantitative scales are mainly used, giving rise to the clarity and objectiveness in assessment. This third reason has been highlighted by the interviewed managers, given their thought that the evaluation of backstage job performance seems to be more complicated. It should be noted that TM has just been an emerging issue in Vietnamese banking sector; therefore, the primary focus of this kind of practice on easily assessable jobs is understandable. In long term future, when TM becomes a more popularly advanced scheme across Vietnamese banks, the scope of TM will possibly be expanded to more different functions in banks.

This finding of sales orientation in banking is in line with the discussion found in the literature. As explained by (Kosim, et al., 2016), sales skills of banking employees become a very important banking function. Managers evaluate bankers primarily on salesmanship, and secondarily on customer service. It is unforeseeable that future TM programs in the Vietnamese banking sector will put significant emphasis on other jobs besides sales. According to Porter (1998), competitive advantage is derived from many discrete activities within two categories: primary and support activities. All such activities are components of value chains which help to create a competitive advantage for a firm. Consequently, it is apparent that besides sales, there are many other important activities which need the longterm investment of banks to build competitive advantages for sustainable firm growth. Further research may address the application of Porter's argument in examining banking areas in which talent is needed.

\subsection{Talent as High Performers/Potentials (Exclusive) Rather than All Employees (Inclusive)}

It was found that TM is more focused on employees who are high performers or high potentials, rather than on all staff who are managed under the narrow notions of HRM practices (exclusive more than inclusive approach). This is in line with the exclusive perception based on workforce segmentation (Tansley et al., 2007). In fact, the exclusive approach is the most widespread approach to TM found in HR practice (Höglund, 2012).

The finding also indicates that talent as high performer is the main approach applied in the public and foreign banking sectors, which is due to those banks' strategies, culture and HRM preferences. 'Talent as high performers' refers to a group of top-ranking employees in terms of capability and performance (Stahl et al., 2012). This approach is consistent with the output perspective, which focuses on output, performance, achievements and results (Mensah, 2015). From these organizations' perspective, identifying talent based on performance data is commonly used as it is less politically charged than identification based on motivational variables related to the input perspective (Silzer \& Church, 2010).

The finding from this research is partially similar to that of Bist and Srivastava (2013) and Athawale et al. (2013), who found that talent in the private banking sector is identified by competency (high potential), meanwhile, in the public sector, it is identified by results (high performance). There is still limited research, if any, which addresses differences between types of banks regarding talent identification. The above discussions highlight the theoretical significance, which was previously underlined in the introduction. The practical implications of this study are also presented below in the conclusion section.

\section{Conclusion}

Results of this study reveal that banking talent is defined as a combination of interconnected and interdependent soft skills, learning ability, flexibility, technology adaptability, integrity and risk management skills. Additionally, bank talent is mostly related to sales jobs. Remarkably, talent in the private banking sector, which has implemented efficient TM programs, is identified by not only results (high performance), but also competency (high potential). However, in the public and foreign banking sectors, as well as in those private banks where TM practices have not been well undertaken, talent is mostly identified by results (high performance).

The implications of these findings indicate that banks should utilize their home-grown talent to meet current and future needs. It is also recommended that the banking community and practitioners understand that not only training, but also an increasing focus, should be imparted to soft skills development and integrity control in order to foster employee performance and attitudes. Besides, due to the rising importance of digital talent in the banking sector, managers should also give more consideration to technological innovations and provide more support to enhance employees' technology adaptability. Attention should be paid to not only sales positions but also to other positions within the bank. Last, but not least, talent mindsets, involving sympathy and trust, are highly necessary to create encouraging conditions for bank talents to learn and grow.

It is recognized that this study has a number of limitations: (1) the authors wish to expand this study in the future, based on a higher number of banks and HR consulting firms; (2) cross-checking the findings of the study was not covered; 
its reliability and validity would be increased through methodological triangulation, usage of qualitative research methods and the addition of other data collection techniques; (3) absence of the perspectives of talented employees, highlevel managers and other stakeholders of the banks. Future research should consider the aforementioned limitations and may also study the TM issue in another industry or in multi sectors to test the generalizability of the findings.

\section{References}

Ariss, A., Vassilopoulou, J., Özbilgin, M. F., \& Game, A. (2013). Understanding career experiences of skilled minority ethnic workers in France and Germany. The International Journal of Human Resource Management, 24(6), 1236-1256.

Athawale, R. M., Todkar, R. V \& Ghansawant, R. S. (2013). The Need Of Talent Management in Public Sector Banks in India, International Journal of Human Resource Management and Research, 3(5), 37-42.

Bist, S. S., \& Srivastava, N. (2013). Talent management scenario in the banking industry. Paripex-Indian Journal of Research, 2(4), 274-276.

Boatright, J. R. (2011). Trust and integrity in banking. Ethical perspectives, 18(4), 473.

Buckingham, M., \& Vosburgh, R. M. (2001). The 21st century human resources function: It's the talent, stupid!. Human Resource Planning, 24(4), 17-23.

Cooke, F. L., Saini, D. S., \& Wang, J. (2014). Talent management in China and India: A comparison of management perceptions and human resource practices. Journal of World Business, 49(2), 225-235.

Dang, N. T. T., Nguyen, Q. T. \& Habaradas, R. (2019). Talent Conceptualization and Talent Management within the Banking Sector in Southern Vietnam [Paper presentation]. The 34th IBIMA International Conference. Madrid.

Deloitte. (2019). Banking and Capital Markets Outlook 2019. Deloitte. Retrieved January 10, 2020, from: https://www2. deloitte.com/content/dam/Deloitte/global/Documents/ Financial-ervices/gx-fsi-dcfs-2019-banking-cap-marketsoutlook.pdf

Do, D. T., Nguyen, T. H., Nguyen, T. H. N., Ha, H. H., \& Le, T. T. (2020). The Influence of Leadership Style on Accountants' Commitment with Enterprise: An Empirical Study on Vietnamese FDI Firms. Journal of Asian Finance, Economics and Business, 7(3), 235-243. https://doi.org/10.13106/ jafeb.2020.vol7.no3.235

Fawal, A., \& Mawlawi, A. (2018). The Corporate Governance and Its Effect on the Marketing Performance Strategy in the Lebanese Banking Sector. Management, 8(3), 86-93.

Gaji, M. B., Kassim, R. N. M., \& Raju, V. (2017). Integrity, Trust and Nigerian Banks' Employee Engagement. International Journal of Business Management and Economic Research, 8(4), 982986.
Gallardo-Gallardo, E., Dries, N., \& González-Cruz, T. F. (2013). What is the meaning of 'talent' in the world of work? Human Resource Management Review, 23(4), 290-300.

Gelens, J., Dries, N., Hofmans, J., \& Pepermans, R. (2015). Affective commitment of employees designated as talent: Signalling perceived organisational support. European Journal of International Management, 9(1), 9-27.

Ha, V. D. (2019). Impact of Organizational Culture on the Accounting Information System and Operational Performance of Small and Medium Sized Enterprises in Ho Chi Minh City. Journal of Asian Finance, Economics and Business, 7(2), 301308. https://doi.org/10.13106/jafeb.2020.vol7.no2.301

Hasan, N. A. (2016). The Effect of Talent-and Knowledge Management on the Performance of SMEs: Evidence from Malaysia. Kent, UK: Doctoral dissertation, University of Kent.

Höglund, M. (2012). Quid pro quo? Examining talent management through the lens of psychological contracts. Personnel Review, 41(2), 126-142.

Hosen, S., Islam, M. A., Arshad, M. M., Khan, A. M., \& Alam, M. K. (2018). Talent management: An escalating strategic focus in Bangladeshi banking industry. International Journal of Academic Research in Business and Social Sciences, 8(1), 156-166.

Iles, P. (2013). Commentary on "The meaning of 'talent' in the world of work”. Human Resource Management Review, 23(4), 301-304.

Iles, P., Preece, D., \& Chuai, X. (2010). Talent management as a management fashion in HRD: Towards a research agenda. Human Resource Development International, 13(2), 125-145.

Kim, S., Froese, F. J., \& Cox, A. (2012). Applicant attraction to foreign companies: the case of Japanese companies in Vietnam. Asia Pacific Journal of Human Resources, 50(4), 439-458.

Kosim, Z., Ahmad, N. H., \& Choo, T. S. (2016). Determinants of Sales Force Performance in Banking Sector: A Case of Malaysia. Information Management and Business Review, 8(4), 13-23.

Lucca, D., Seru, A., \& Trebbi, F. (2014). The revolving door and worker flows in banking regulation. Journal of Monetary Economics, 65, 17-32.

Luna-Arocas, R. \& Morley, M. J. (2015). Talent management, talent mindset competency and job performance: The mediating role of job satisfaction. European Journal of International Management, 9(1), 28-51.

Mensah, J. K. (2015). A "coalesced framework" of talent management and employee performance. International Journal of Productivity and Performance Management, 64(4), 544-566.

Meyers, M. C., Van Woerkom, M., \& Dries, N. (2013). TalentInnate or acquired? Theoretical considerations and their implications for talent management. Human Resource Management Review, 23(4), 305-321. 
Nguyen, D. T. N., Teo, S. T., \& Ho, M. (2018). Development of human resource management in Vietnam: A semantic analysis. Asia Pacific Journal of Management, 35(1), 241-284.

Nzewi, H., Chiekezie, O., \& Ogbeta, M. (2015). Talent management and employee performance in selected commercial banks in Asaba, Delta State, Nigeria. European Journal of Business and Social Sciences, 4(09), 56-71.

Porter, M. E. (1998). Clusters and the new economics of competition. Harvard Business Review. 76(6), 77-90.

Ready, D. A., Conger, J. A., \& Hill, L. A. (2010). Are you a high potential. Harvard business review, 88(6), 78-84.

Saunders, M., Lewis, P., \& Thornhill, A. (2015). Research Methods for Business Students (7th New ed). New York: Pearson (Intl).

Shukla, S and Nayak, G. (2016), Banks Now Bet on Young and Technology-Savvy Talent With Special 'Skill Sets'. The Economic Times. Retrieved January 10, 2020, from: https:/economictimes.indiatimes.com/industry/banking/ finance/banking/banks-now-bet-on-young-and-technologysavvy-talent-with-special-skill sets/articleshow/50714117. $\mathrm{cms}$ ?from $=\mathrm{mdr}$

Silzer, R., \& Church, A. H. (2010). Identifying and assessing high-potential talent. Strategy-driven talent management: A leadership imperative, 28, 213-280.
Soto, P. E. (2019). Breaking the Word Bank: Effects of Verbal Uncertainty on Bank Behavior. FDIC Center for Financial Research Paper, (2019-01).

Stahl, G., Björkman, I., Farndale, E., Morris, S. S., Paauwe, J., Stiles, P., \& Wright, P. (2012). Six principles of effective global talent management. Sloan Management Review, 53(2), 25-42.

Tansley, C., Turner, P., Foster, C., Harris, L., Stewart, J., Sempik and Williams, H. (2007). Talent: Strategy, Management, Measurement. New York, NY: McGraw-Hill Education.

Thunnissen, M., \& Buttiens, D. (2017). Talent management in public sector organizations: A study on the impact of contextual factors on the TM approach in Flemish and Dutch public sector organizations. Public Personnel Management, 46(4), 391-418.

Tran, D. T., Lee, L. Y., Nguyen, P. T., \& Srisittiratkul, W. (2019). How Leader Characteristics and Leader Member Exchange Lead to Social Capital and Job Performance. Journal of Asian Finance, Economics and Business, 7(1), 269-278. https://doi.org/10.13106/jafeb.2020.vol7.no1.269

Zhu, Y., \& Verstraeten, M. (2013). Human resource management practices with Vietnamese characteristics: a study of managers' responses. Asia Pacific Journal of Human Resources, 51(2), 152-174. 